Kanishka Chowdhury, ${ }^{1}$ MBBS, MS ENT, Somnath Saha,MBBS, MS ENT, Sudipta Pal, ${ }^{1}$ MBBS, MS ENT, Indranil Chatterjee ${ }^{2}$ MASLP

'Department of ENT, R.G.Kar Medical College \& Hospital, Kolkata

${ }^{2}$ Ali Yavar Jung National Institute for the Hearing

Handicapped, Kolkato

\section{Effects of Type 3 Thyroplasty on Voice Quality Outcomes in Puberphonia}

\begin{abstract}
Objectives: To assess effects of type 3 thyroplasty on outcomes of voice quality in puberphonia. Methods:

Design: Prospective Cohort

Setting: Tertiary Referral Hospital

Participants: Six patients with puberphonia who failed voice therapy, aged 16-25 years, who consulted at the ENT Outpatient department between September 2010 and September 2012, underwent type 3 thyroplasty.

Pre-operative and 6-month post-operative voice analysis by voice recordings, Voice Handicap Index (VHI), GRBAS score and real time acoustic analysis (perturbation) using Dr Speech software (University version 4.0, Voice Tech Corporation, USA [Tiger Electronics]) with habitual fundamental frequency (F0), jitter \% and shimmer \% as parameters were performed.
\end{abstract}

Results: Mean pre-operative VHI and GRBAS scores were 53 and 75.67, respectively, whereas post-operative scores were 29 and 25.00, respectively. (P-value for VHI was 0.004 and that of GRBAS was 0.00). On acoustic analysis, mean pre-operative habitual fundamental frequency (F0), jitter $\%$ and shimmer $\%$ was $245.82 \mathrm{~Hz}, 0.21$ and 2.34 , respectively, whereas post-operative mean was $140.78 \mathrm{~Hz}(P=0.00), 0.19(P=0.04)$ and $1.52(P=0.00)$, respectively.

Conclusion: The mainstay of treatment of puberphonia is voice therapy. Thyroplasty provides a suitable management option in those cases who fail to respond by voice therapy.

Keywords: puberphonia, thyroplasty, laryngeal framework surgery, voice analysis

Puberphonia is a condition affecting young men between ages 11-15 with an incidence of $1 / 900,000$ per year. ${ }^{1,2}$ It presents with increased pitch or fundamental frequency, weak, breathy, hoarse voice, pitch breaks, low intensity and psychological symptoms. ${ }^{1}$ At puberty, the voice needs to be retrained in order to cope with the larger larynx. Most boys adjust to this new change of voice. But a few do not make the transition into using their deeper voice and continue to use the high-pitched voice. This is labeled 'puberphonia.' So puberphonia, also called mutational falsetto, functional falsetto or persistent falsetto is defined as a post-adolescent male continuing to have a pre-adolescent voice. . $^{3,4}$

Philipp J Otolaryngol Head Neck Surg 2014; 29 (1): 6-10

(c) Philippine Society of Otolaryngology - Head and Neck Surgery, Inc 
Outcome assessment of results of puberphonia therapy can be done in terms of different aspects of voice evaluation which includes subjective evaluation of voice, perceptual evaluation of voice and acoustic analysis along with traditional voice recordings. ${ }^{3}$ Subjective evaluation is basically a patient scale. Patient scales typically measure patient satisfaction, quality of life, general health, handicap or loss as a result of the voice disorder or some aspect of voice production. ${ }^{3}$ Several scales specific to voice have been used such as Voice Handicap Index (VHI) and Voice-Related Quality of Life (V-RQOL). Perceptual evaluation of voice can be done using various scales such as GRBAS, CAPE-V and Buffalo III. There are various parameters such as fundamental frequency, intensity, perturbation measures (shimmer\%, jitter \%) which are measured as part of acoustic analysis. In the present study, we tried to evaluate the effects of type 3 thyroplasty on voice outcome in puberphonia using these tools of voice analysis along with conventional recording of voice.

\section{METHODS}

This was a prospective cohort of puberphonia patients attending the ENT outpatient department of a tertiary referral hospital in eastern India between September 2010 and September 2012. Institutional ethical review board approval as well as informed consent was taken. Patients 15 years of age and above were included in the study. All patients were given voice therapy (primal sound production with cough and digital manipulation thrice weekly, each session for 30 minutes over three months) by three speech pathologists. As the results of voice improvement were not satisfactory, six patients underwent type 3 thyroplasty. The voice improvement was unsatisfactory in terms of: 1) Shifting of fundamental frequency (F0) was not stable: 2) Threemonth therapy sessions (30 minutes daily) did not give them adequate improvement in conversational speech: and 3) Lack of motivation that affected improvement pattern. Patients included in the study were those who failed after voice therapy, without any psychological abnormality including transsexualism, no endocrine abnormality, no chronic pulmonary problems and no anesthetic contraindications.

All operations were performed under local anesthesia. After thyroid cartilage exposure via midline approach, the thyroid cartilage midline was identified. (Figure 1) Perichondrium was elevated from the thyroid cartilage. A parallel incision to midline was made on both sides up to the inner perichondrium without incising it and $1.5 \mathrm{~mm}$ strips of cartilage were incised on either side of the midline of the thyroid cartilage with a knife. (Figure 2) Peri-operative voice assessment was made after pushing the mid portion of the cartilage. The free borders of the thyroid cartilage were approximated with 2-0 prolene sutures and the wound was closed in layers. (Figure 3) Pre-operative and 6-month post-operative comparison of voice recordings was performed by three trained listeners consisting of one otorhinolaryngologist with five years of experience in phonosurgery and two post-graduate speech language pathologists with five years of experience, VHI score, GRBAS score (we extra-plotted the GRBAS score into a 100 point visual analogue scale to increase specificity) and real time acoustic analysis (perturbation) of voice using Dr Speech software (University version 4.0, Voice Tech Corporation, USA [Tiger Electronics]) (habitual fundamental frequency (F0), jitter \% and shimmer \% as parameters). Statistical analysis was done using paired-t test with finite population correction (as sample size was small) using SPSS software (version 17.0, IBM, USA).

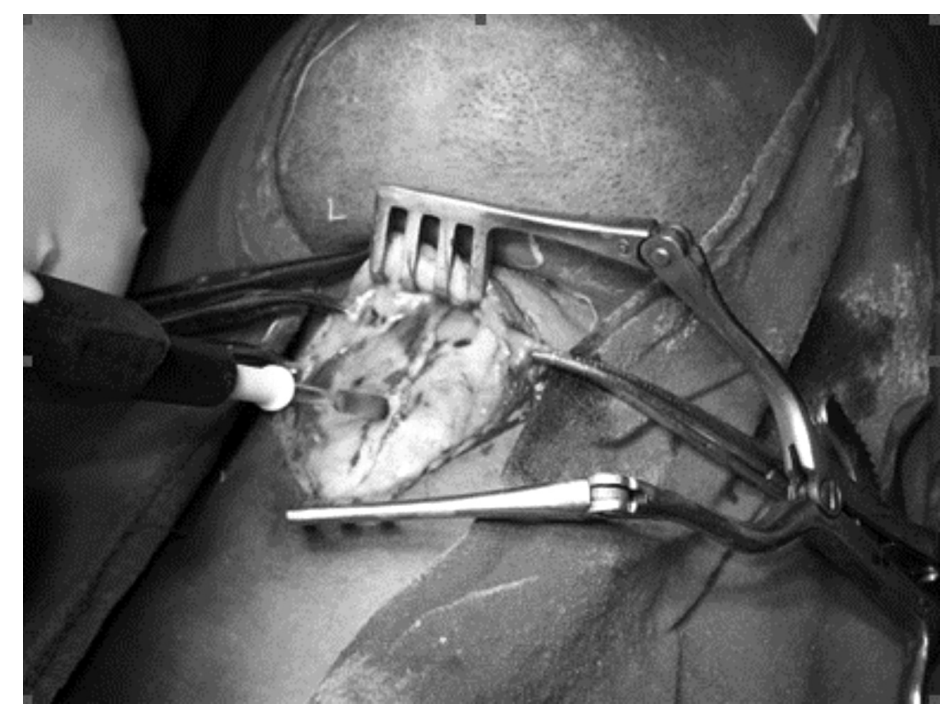

Figure 1. Delineation of Midline of Thyroid Cartilage

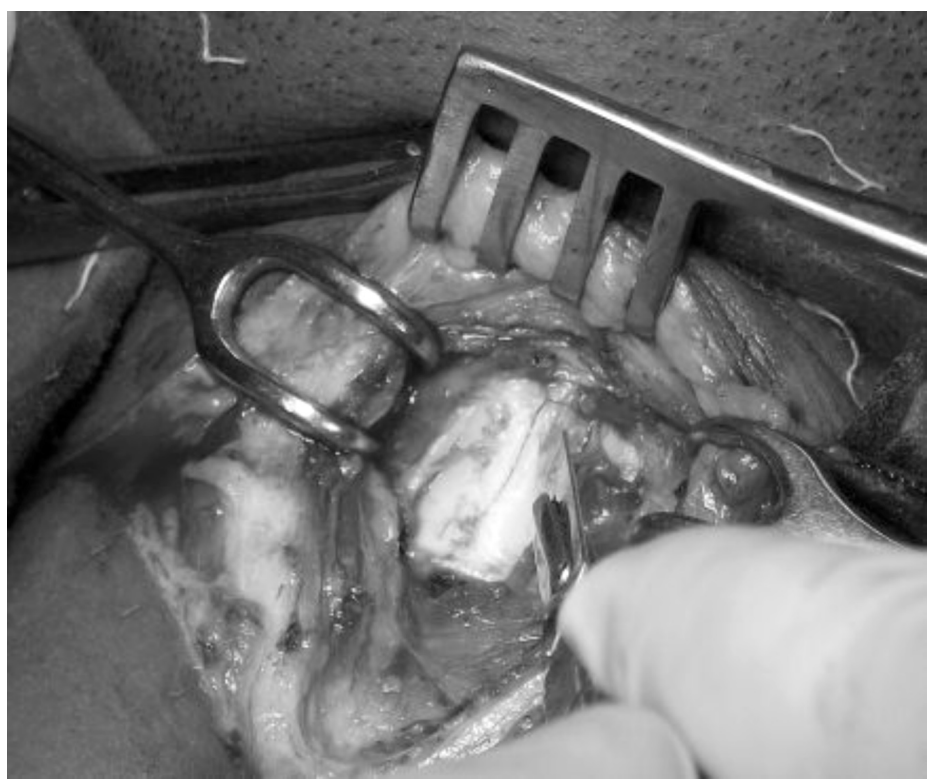

Figure 2. Making Incision Lateral to Midline of Thyroid Cartilage 


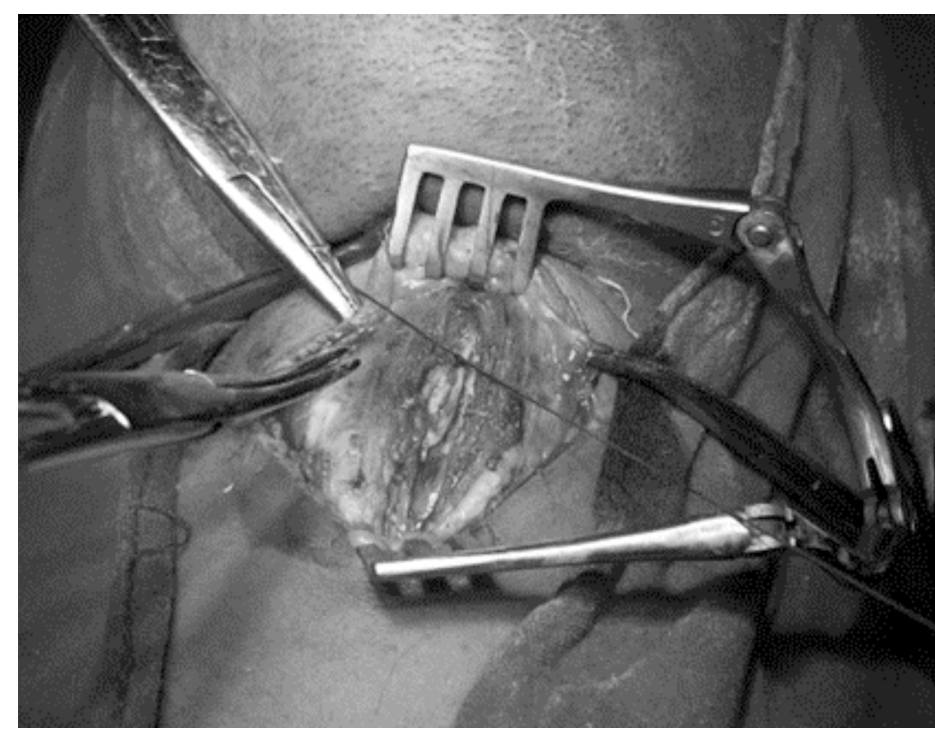

Figure 3. Suturing Two Sides of Ala of Thyroid Cartilage

\section{RESULTS}

A total of six patients underwent surgery. Their ages ranged from 16-25 years (mean age 19 years). The mean pre-operative VHI score was 53 and post-operative was 29. Paired t test result showed that $t=$ $0.004(P<0.05)$ which was significant. The mean pre-operative GRBAS score was 75.67 whereas post-operative score was 25.00 . Paired $t$ test result showed that $t=0.000(P<0.05)$ which was significant. Results of acoustic analysis of voice revealed mean pre operative habitual fundamental frequency; jitter \% and shimmer $\% 245.82 \mathrm{~Hz}, 0.21$ and 2.34, respectively. (Table 1) The mean post-operative values for the same parameters showed $140.78 \mathrm{~Hz}, 0.19$ and 1.52 , respectively. Paired $t$ test result of habitual fundamental frequency showed that $t=0.00$ ( $P$ $<0.05)$ which was significant. Paired $t$ test result of jitter $\%$ showed that $t=0.04(P<0.05)$ which was significant. Paired $t$ test result of shimmer $\%$ showed that $t=0.00(P<0.05)$ which was significant. There were no early or late postoperative complications. The post-operative voice was improved in all patients.

Table 1. Results of acoustic analysis using Dr Speech software (University version 4.0)

\begin{tabular}{|c|c|c|c|c|c|}
$\begin{array}{c}\text { Pre op } \\
\text { habitual } \\
\text { F0 (Hz) }\end{array}$ & $\begin{array}{c}\text { Pre op } \\
\text { jitter \% }\end{array}$ & $\begin{array}{c}\text { Pre op } \\
\text { shimmer } \\
\%\end{array}$ & $\begin{array}{c}\text { Post op } \\
\text { habitual } \\
\text { F0 (Hz) }\end{array}$ & $\begin{array}{c}\text { Post op } \\
\text { jitter \% }\end{array}$ & $\begin{array}{c}\text { Post op } \\
\text { shimmer } \\
\%\end{array}$ \\
\hline 249.07 & 0.21 & 2.16 & 128.51 & 0.22 & 1.48 \\
\hline 244.98 & 0.19 & 2.62 & 180.24 & 0.18 & 1.6 \\
\hline 252.67 & 0.24 & 2.24 & 136.68 & 0.19 & 1.42 \\
\hline 250.24 & 0.22 & 2.62 & 140.24 & 0.2 & 1.64 \\
\hline 229.32 & 0.18 & 2.22 & 128.38 & 0.14 & 1.4 \\
\hline 248.64 & 0.24 & 2.18 & 130.64 & 0.19 & 1.58 \\
\hline
\end{tabular}

\section{DISCUSSION}

Puberphonia, also called mutational falsetto, functional falsetto or persistent falsetto is a disorder of adolescent males and can be defined as a post adolescent male continuing to have a pre adolescent voice. ${ }^{3,4}$ During infancy the laryngo-tracheal complex is situated at a higher level that gradually descends throughout life. ${ }^{2}$ The descent of larynx is most pronounced during puberty when there is also a sudden increase in the size of larynx under the influence of testosterone. This results in a voice change in the males during adolescence between 12 and 15 years of age. This voice change can be well appreciated as it changes from a high-pitched voice to a low-pitched voice. At puberty the voice thus needs to be retrained in order to cope with the larger larynx. Most boys adjust to this new change of voice. But a few do not make the transition into using their deeper voice and continue to use the prepubertal highpitched voice. This is labeled as 'Puberphonia' where the larynx fails to descend and tends to be held high in the neck.

The etiologies of puberphonia have been posited to include resisting change of puberty, habitual pitch, disliking new pitch after puberty, new pitch not matching personality, wanting to remain young, more identification with females, singing voice, embarrassment and anatomical differences. ${ }^{5,6}$

The treatment of choice for puberphonia is voice therapy with which most of the patients improve. ${ }^{7,8}$ However, patients who fail to improve with conservative management should be considered for other modalities of treatment as delayed treatment and denial of the problem causes the disorder to become recalcitrant to behavioral treatment. Direct laryngoscopic manipulation has been described by Vaidya et al. where pressure was applied onto the valleculae internally by laryngoscope and externally on the thyroid cartilage with immediate improvement of pitch. ${ }^{9}$

Isshiki type 3 thyroplasty can be considered to be a definitive treatment for puberphonia as vocal pitch has been shown to be effectively lowered by this surgery without distorting the vocal quality. ${ }^{10}$ Pau and Murty (2001) were the first to report a surgically corrected case of puberphonia where they attempted surgical lowering of the hyoid and larynx in a 24-year-old male resulting in lowering of pitch from $175 \mathrm{~Hz}$ to $142 \mathrm{~Hz}$. ${ }^{2}$ They mobilized the hyoid and superior halves of thyroid cartilage and reduced cricothyroid distance by apposing mobile hyoid to fixed cartilage by two non-absorbable figure of 8 sutures. However, in the classic Isshiki type 3 thyroplasty, $2-3 \mathrm{~mm}$ of vertical strips of cartilage were excised on each side of midline of thyroid cartilage. ${ }^{10}$ This procedure caused retrusion of the middle portion of the thyroid cartilage causing a reduction in the length of the vocal folds. The procedure is termed as relaxation thyroplasty by a medial approach (anterior commissure retrusion) as proposed by the Phonosurgery Committee of the European Laryngological Society. ${ }^{11}$ According to Isshiki et al. vocal cord stiffness is seen in dysphonia that is suggested by a breathy, high pitched and strained voice. Surgical A-P 
ORIGINAL ARTICLES

shortening of thyroid ala reduced the stiffness of the cord thus treating it successfully. ${ }^{12}$

In our study, we performed the classic Isshiki type 3 thyroplasty in six puberphonia patients with high pitched voice who failed to improve with voice therapy. Postoperatively there was successful lowering of the vocal pitch. Remacle et al. has shown type 3 thyroplasty to be a successful treatment option for lowering vocal pitch in cases of mutational falsetto voice recalcitrant to conservative therapy. ${ }^{13}$

Li et al. performed acoustic evaluation of Isshiki type 3 thyroplasty for treatment of mutational voice disorders in 11 male patients and concluded that the pre-operative high pitched voices of all the male patients were lowered up to the normal value by type 3 thyroplasty. ${ }^{14}$

Slavith et al.assessed the role of type 3 thyroplasty using preoperative and postoperative voice recordings as well as electroglottography and photoglottography. ${ }^{15}$ Analysis of the preoperative and postoperative data from two patients with over one year follow-up showed a decrease in frequency of vibration. Postoperatively, the vocal folds still vibrated in a regular pattern as described by the myoelastic-aerodynamic theory without any increase in jitter or shimmer quotient. They concluded that type 3 thyroplasty is capable of lowering the fundamental frequency of speech without adversely affecting the vibratory mode of the vocal folds.

Different modifications of type 3 Isshiki thyroplasty have been proposed by various authors. Tucker's procedure is less invasive whereby a superiorly based cartilage window is created at the level of anterior commissure and is pushed behind causing relaxation of the vocal folds. ${ }^{16}$ This surgical procedure is very useful in treating patients in whom psychological counseling and voice therapy have failed.

Kocak et al. assessed the success rate of a less invasive modification of Isshiki type 3 thyroplasty by performing window anterior commissure relaxation laryngoplasty technique in patients with high-pitched voice disorders. ${ }^{17}$ Among 21 patients with a mean age of 30.5 years, the most frequent cause of high-pitched voice was sulcus vocalis $(n=14)$, followed by constitutional causes $(n=5)$, mutational falsetto $(n=1)$ and severe glottic scarring secondary to childhood diphtheria $(n=1)$. After surgery, the fundamental frequency dropped significantly from a mean of $213.81 \mathrm{~Hz}$ to $149.86 \mathrm{~Hz}(\mathrm{P}<0.001)$ equaling a mean postoperative semitone drop of 6.23 .

García-López et al. presented a case of a patient with dysphonia by tone elevation in relation to gender treated by type 3 thyroplasty and an updated review of the surgical technique and its outcome. ${ }^{18}$ Chandra et al. also performed Issiki's type 3 thyroplasty in seven patients with puberphonia. ${ }^{19}$ Average pre and post-operative mean pitch was 224.42 and $137, \mathrm{~Hz}$ respectively.

In the present series, we included only patients whose voice did not improved even after extensive voice therapy sessions. After type 3 thyroplasty, there was improvement of all the parameters of acoustic analysis. Though jitter and shimmer percentage improved, the most
Table 2. Results of type 3 thyroplasty on puberphonic patients in different studies

\begin{tabular}{|c|c|c|c|c|}
\hline $\begin{array}{c}\text { Author(s) } \\
\text { / Year }\end{array}$ & Journal & Subjects & Parameters & Results \\
\hline $\begin{array}{l}\text { Slavit DH, Mara- } \\
\text { gos NE, Lipton RJ. } \\
/ 1990\end{array}$ & Laryngoscope & 2 male patients & \begin{tabular}{|l|} 
Voice recordings, \\
electroglottography, \\
photoglottography
\end{tabular} & \\
\hline $\begin{array}{l}\text { Li GD, Mu L, Yang } \\
\text { S. /1999 }\end{array}$ & $\begin{array}{l}\text { Journal of Laryn- } \\
\text { gology \& Otology }\end{array}$ & 11 male patients & $\begin{array}{l}\text { Fundamental } \\
\text { frequency (Fo), } \\
\text { voice frequencies, } \\
\text { and vocal inten- } \\
\text { sity obtained from } \\
\text { a sustained vowel } \\
\text { /i/ during different } \\
\text { phonatory tasks }\end{array}$ & \begin{tabular}{|l|} 
Post operative \\
voice frequencies \\
were significantly \\
decreased ( $p<0.05$ ) \\
without any statisti- \\
cally significant \\
differences in the \\
pre- and post- \\
operative measures \\
of vocal intensity ( $p$ \\
$>0.5)$. \\
\end{tabular} \\
\hline $\begin{array}{l}\text { Kizilay A, Firat Y } \\
/ 2008\end{array}$ & $\begin{array}{l}\text { Turkish Journal } \\
\text { of Ear Nose and } \\
\text { Throat }\end{array}$ & \begin{tabular}{|l|}
16 male patients \\
(Treatment given \\
mainly voice thera- \\
py. Thyroplasty was \\
done in 1 patient \\
who failed after \\
voice therapy)
\end{tabular} & $\begin{array}{l}\text { Voice handicap } \\
\text { index (VHII) and } \\
\text { videolaryngostro- } \\
\text { boscopy (VLS), } \\
\text { fundamental } \\
\text { frequency(F0), } \\
\text { jitter, shimmer and } \\
\text { normalized noise } \\
\text { energy(NNE) }\end{array}$ & $\begin{array}{l}\text { All scores of the VHI } \\
\text { showed significant } \\
\text { improvements } \\
\text { (p=0.001). Among } \\
\text { acoustic parameters, } \\
\text { only the mean fun- } \\
\text { damental frequency } \\
\text { showed a significant } \\
\text { change from } 246 \mathrm{~Hz} \\
\text { to } 134 \mathrm{~Hz} \text { after treat- } \\
\text { ment }(\mathrm{p}=0.001)\end{array}$ \\
\hline $\begin{array}{l}\text { Kocak I, Dogan M, } \\
\text { Tadihan E, Alkan } \\
\text { Cakir Z, Bengisu S, } \\
\text { Akpinar M. } \\
\text { /2008 }\end{array}$ & $\begin{array}{l}\text { Archives of } \\
\text { Otolaryngology } \\
\text { - Head and Neck } \\
\text { Surgery }\end{array}$ & \begin{tabular}{|l|}
21 patients with \\
high-pitched voice \\
including 1 patient \\
with puberphopnia
\end{tabular} & \begin{tabular}{|l|} 
Fundamental fre- \\
quency (F0), diplo- \\
phonia, perception \\
of body image and \\
pitch and subjective \\
ratings of comfort \\
during vocalization.
\end{tabular} & \begin{tabular}{|l|} 
Fundamental fre- \\
quency dropped \\
significantly from a \\
mean of $213.81 \mathrm{~Hz}$ \\
to $149.86 \mathrm{~Hz}(\mathrm{P}<$ \\
$.001)$. Misperception \\
leading to an ab- \\
normal body image \\
was reduced by \\
$86 \%$. Diplophonia \\
with subharmonic \\
signals was reduced \\
or disappeared in \\
6 cases. \\
\end{tabular} \\
\hline $\begin{array}{l}\text { Remacle M, Matar } \\
\text { N, Verduyckt I, } \\
\text { Lawson G } \\
/ 2010\end{array}$ & $\begin{array}{l}\text { The Annals of } \\
\text { Otology, } \\
\text { Rhinology, and } \\
\text { Laryngology }\end{array}$ & $\begin{array}{l}7 \text { male patients with } \\
\text { a mean age of } 21 \\
\text { years }\end{array}$ & \begin{tabular}{|l|} 
Fundamental \\
frequency (F0) of \\
the voice and Voice \\
Handicap Index \\
(VHI)
\end{tabular} & $\begin{array}{l}\text { Mean fundamental } \\
\text { frequency was low- } \\
\text { ered from } 187 \mathrm{~Hz} \text { to } \\
104 \mathrm{~Hz}(p<0.001) \text {, } \\
\text { and the mean Voice } \\
\text { Handicap Index was } \\
\text { improved from } 70 \\
\text { to } 21 \text {. }\end{array}$ \\
\hline $\begin{array}{l}\text { Chandra ST, Rao } \\
\text { SM, Kumar AY, } \\
\text { Murty PSN } \\
\text { /2011 }\end{array}$ & $\begin{array}{l}\text { International } \\
\text { Journal of } \\
\text { Phonosurgery } \\
\text { and Laryngology }\end{array}$ & 7 male patients & Mean pitch in $\mathrm{Hz}$ & \begin{tabular}{|l|} 
Average pre and \\
post-operative \\
mean pitch was \\
224.42 and $137 \mathrm{~Hz}$ \\
respectively \\
Mean pre-operative \\
VHI and GRBAS \\
score were 53 and \\
75.67 respectively \\
whereas post-oper- \\
ative score were 29 \\
and 25 respectively.
\end{tabular} \\
\hline $\begin{array}{l}\text { Chowdhury K, } \\
\text { Saha S, Pal S, } \\
\text { Chatterjee I/ } \\
\text { 2014(Present } \\
\text { study) }\end{array}$ & $\begin{array}{l}\text { Philippine Journal } \\
\text { of Otolaryngology } \\
\text { Head and Neck } \\
\text { Surgery }\end{array}$ & $\begin{array}{l}6 \text { male patients with } \\
\text { a mean age of } 19 \\
\text { years }\end{array}$ & $\begin{array}{l}\text { Voice recording by } \\
\text { trained listener, VH } \\
\text { score, GRBAS and } \\
\text { real time acoustic } \\
\text { analysis (perturba- } \\
\text { tion) of voice using } \\
\text { Dr Speech software } \\
\text { (University version } \\
\text { 4.0) (habitual fun- } \\
\text { damental frequency } \\
\text { (F0), jitter \% and } \\
\text { shimmer \% }\end{array}$ & $\begin{array}{l}\text { Mean pre-operative } \\
\text { habitual fundamen- } \\
\text { tal frequency (F0), } \\
\text { jitter \% and shim- } \\
\text { mer \% was } 245.82 \\
\mathrm{~Hz}, 0.21 \text { and } 2.34 \\
\text { respectively where- } \\
\text { as post-operative } \\
\text { mean was } 140.78 \\
\mathrm{~Hz}, 0.19 \text { and } 1.52 \\
\text { respectively. }\end{array}$ \\
\hline
\end{tabular}


significant change was with fundamental frequency (mean preoperative 245.82 to mean post-operative $140.78 \mathrm{~Hz}, \mathrm{P}=0.001$ ). There was also significant subjective improvement of the patients as evident by $\mathrm{VHI}$ score (from pre-operative 53 to post-operative 29, $\mathrm{p}=0.004$ ). Results of type 3 thyroplasty on puberphonic patients in different studies are summarized in Table 2.

The treatment of choice for puberphonia is voice therapy. The main difficulties encountered in the treatment of puberphonia with voice therapy include stabilization of the attained fundamental frequency (F0) and widening the frequency range. Type 3 thyroplasty can offer a suitable management option in those cases that fail to respond to voice therapy or fail to sustain the results. Outcomes of surgery can be assessed by subjective improvement scales (e.g. VHI), perceptual scales (e.g. GRBAS) as well as real time acoustic analysis apart from traditional voice recordings.

\section{REFERENCES}

1. Dagli M, Sati I, Acar A, Stone RE Jr, Dursun G, Eryilmaz A. Mutational falsetto: intervention outcomes in 45 patients. J Laryngol Otol.2008 Mar; 122(3):277-281.

2. Pau H, Murty GE. First case of surgically corrected puberphonia. J Laryngol Otol. 2001 Jan; 115(1):60-61.

3. Flint PW, Haughey BH, Lund VJ, Niparko JK, Richardson MA, Robbins KT, Thomas JR, editors. Cummings Otolaryngology-Head and Neck Surgery. $5^{\text {th }}$ ed. NY: Elsevier; 2010.

4. Stemple JC, Glaze LE, Klaben BG. Clinical voice pathology: theory and management. 3rd ed. NY: Delmar Cengage Learning; 2000.

5. Nicolosi L, Harryman E, Kresheck J. Terminology of communication disorders: speech-languagehearing. 5th ed. Baltimore: Lippincott Williams \& Wikins; 2004.

6. Hedge MN. Introduction to communicative disorders, 3rd ed. Austin, TX: Pro-Ed; 2001

7. Harris S. Speech therapy for dysphonia. In: Harris T, Harris S, Rubin JS, Howard DM, editors. The voice clinic handbook. London: Whurr Publishers Ltd. 1998;139-206.

8. Carlson E. Electrolaryngography in the assessment and treatment of incomplete mutation (puberphonia) in adults. Eur J Disord Commun. 1995; 30(2): 140-8.

9. Vaidya S, Vyas G. Puberphonia: A novel approach to treatment. Indian J Otolaryngol Head Neck Surg. 2006 Jan; 58(1):20-1.

10. Isshiki N, Taira T, Tanabe M. Surgical alteration of the vocal pitch. J Otolaryngol. 1983 Oct; 12(5): 335-40.

11. Friedrich G, de Jong FI, Mahieu HF, Benninger MS, Isshiki N. Laryngeal framework surgery: a proposal for classification and nomenclature by the Phonosurgery Committee of the European Laryngological Society. Eur Arch Otorhinolaryngol. 2001 Oct; 258(8): 389-396.

12. Isshiki N, Ohkawa M, Goto M. Stiffness of the vocal cord in dysphonia- its assessment and treatment. Acta Otolaryngol Suppl. 1984; 419:167-174.

13. Remacle M, Matar N, Verduyckt I, Lawson G. Relaxation thyroplasty for mutational falsetto treatment. Ann Otol Rhinol Laryngol. 2010 Feb; 119(2):105-9.

14. Li GD, Mu L, Yang S. Acoustic evaluation of Isshiki type III thyroplasty for treatment of mutational voice disorders. J Laryngol Otol. 1999 Jan; 113(1):31-4.

15. Slavit DH, Maragos NE, Lipton RJ. Physiologic assessment of Isshiki type III thyroplasty. Laryngoscope. 1990 Aug; 100(8): 844-8.

16.Tucker HM, editor. The Larynx. $2^{\text {nd }}$ ed. New York: Thieme; 1992.

17. Kocak I, Dogan M, Tadihan E, Alkan Cakir Z, Bengisu S, Akpinar M. Window anterior commissure relaxation laryngoplasty in the management of high-pitched voice disorders. Arch Otolaryngol Head Neck Surg. 2008 Dec; 134(12):1263-9.

18. García-López I, Peñarrocha J, Gavilan J. [Type III thyroplasty for the treatment of high-pitched voice disorder]. ]. Acta Otorrinolaringol Esp. 2010 Jul-Aug; 61(4): 318-20.

19. Chandra ST, Rao SM, Kumar AY, Murthy PSN. Puberphonia. Int J Phonosurg Laryngol. 2011 JanJun; 1(1): 19-20.

20. Kizilay A, Firat Y. Treatment algorithm for patients with puberphonia. Turkish J Ear Nose Throat. 2008 Nov-Dec; 18(6): 335-42 